\title{
Orquestra como espaço de sonoridades plurais: ética, inclusão ou reclusão
}

Fernando José Monteiro da Costa*

Resumo: A Orquestra tem-se revelado, ao longo dos tempos, como um dispositivo poderoso de participação, mas que parece não ter sido aproveitado nas suas completas potencialidades. Ela surge, fundamentalmente, como um espaço de visibilidade artística, de grande tecnologia, que o pode ser, mas que obnubila uma outra sua perspectiva, quando não se enquadra numa abertura à essência da comunicação. As orquestras de integração podem ser, afinal, essa plataforma, à volta da qual, se devem tecer compromissos, mobilização e, sobretudo, afeição e emoção.

Palavras-chave: Orquestra; Sala de aula; Inclusão; Participação.

Abstract: The Orchestra has proven, over time, as a powerful device to the participation, but that seems not to have been tapped into their full potential. It arises primarily, as a place of artistic visibility, high technology, that can be, but that his could keep another perspective, when an opening does not fit the essence of communication. The orchestras of integration can be, after all, that platform, around which, should weave commitments, mobilization and especially, affection and emotion.

Keywords: Orchestra, Classroom, Inclusion, Participation.

Doutor em História (variante História e Educação), pela Faculdade de Letras da Universidade do Porto e investigador colaborador com o CITCEM (Centro de Investigação Transdisciplinar "Cultura, Espaço, Memória”), da Faculdade de Letras da Universidade do Porto. E-mail: fjmcosta@iol.pt. 


\section{$1^{\circ}$ Argumento}

\section{Inclusão ou integração}

A prática musical coletiva é, sem dúvida, uma plataforma essencial para o desenvolvimento humano. Ela engloba vários aspetos que configuram a revelação artística, o desenvolvimento do estético e do ético, a percepção social e coletiva, a procura do equilíbrio emocional e a promoção de competências criadoras. No referencial quotidiano, as práticas musicais desenvolvem-se em circuito fechado, à volta de metodologias de treino, por vezes, intensivo, quando mesmo, muitas das crianças e jovens apresentam outras vontades e interesses. Através das experiências de anos, fomos verificando que a música pode exercer uma influência singular, como elemento transformador do indivíduo e da comunidade e como fator de uma relação ética com o outro, "no face a face dos seres humanos, na sociabilidade, na sua significação moral" (LEVINAS, 1982, p. 71). Assim, alguns dos contextos mais vulneráveis podem aproveitar do papel importantíssimo que, por exemplo, e porque é o cerne deste artigo, a orquestra tem como centro e periferia da prática coletiva de música. A percepção deste quadro pela reflexão regular trouxe à colação a necessidade de se compreender que viver a música só fará sentido para a criança ou jovem, se todos se sentirem parte do mesmo projeto. Sabemos que a abordagem musical, quer no âmbito do ensino regular obrigatório, quer a partir de muitas das experiências não formais, conduzem a um ensino desvalorizado da música, porque imposto pelo currículo oficial ou por interesses particulares, esquecendo-se que ele só se constrói com o outro, a partir do outro e para o outro, num conceito de legitimidade do outro.

A obsessão técnica tem obnubilado uma tendência criativa, a que a música impele, naturalmente, porque a leitura, a técnica, o treino excessivo em isolamento, pode danificar, em definitivo, a vontade da criança quando decide, ou quando decidem por ela, iniciar uma prática musical. Gainzá prefere $[\ldots]$ "valorizar mais 
os estímulos sonoros e a expressão” (1988, p. 120), pois, assim, estar-se-á a construir um caminho mais sólido e mais sensato para uma aprendizagem significativa da música. O ensino da música in door, quer dizer limitado à sala de aula e centrado numa falsa ideia de diversidade inclusiva, pode conduzir-nos a um modelo insuficiente de participação, para o que David Rodrigues chama à atenção (2003, p. 18-19), implementando-se, acredito que inconscientemente, uma perspectiva de diversidade homogeneizante. Devemos estar claros no paradoxo que o ensino formal, seja ele o que for, gera, quando pretende incluir num espaço de clausura, de reclusão, que se chama de sala de aula, pois, não bastará colocar no mesmo espaço diferentes crianças para se admitir que não existirá qualquer princípio de exclusão. Estamos confrontados com o que Pierre Bourdieu (1993) chamou de "excluídos de dentro". Será que estará construída uma espécie de armadilha na base do binómio inclusão/exclusão?

A ética da inclusão arrasta-nos para a responsabilidade da ação, como uma reflexão primordial sobre valores fundamentais, como o direito à participação, o direito à crítica, o dever de ser considerado. Assim, impóe-se uma finalidade essencial que vence a exploração do ser humano e a sua redução a um simples instrumento. Ele é um fim em si mesmo e a sua participação em qualquer tipo de evento deve ponderar esse postulado relacional. Frequentemente, espera-se que o outro nos devolva um quinhão de favor, na troca da nossa consideração, numa abordagem pouco ética, subjetiva e de, mero, cumprimento de promessas. Verifica-se tal comportamento quando, por exemplo, atribui-se um instrumento a um aluno, por empréstimo ou guarda temporária, ou mesmo definitiva, aguardando-se que ele cumpra, escrupulosamente, o contrato, na medida em que deve devolver uma percentagem de responsabilidade regulada, mas na base de um sentimento que pode danificar a sua própria dignidade. Existe, então, um condicionalismo que exprime negatividade, perante, afinal, uma prática, mais de ética da convicção, do que de ética da responsabilidade, porque nesse caso deverá existir uma preocupação pelas consequências. 
O conceito de inclusão pode, de certa maneira, ser considerado ambíguo na sua formulação, se não forem tidos em consideração alguns pressupostos, até porque, historicamente, a ideia de inclusão nasce relacionada com a pessoa portadora de uma deficiência. Quando alguém é objeto de um processo de inclusão, é porque, naturalmente, encontrava-se excluído, portanto, afastado de qualquer ato de decisão. Fala-se de inclusão na escola, na integração de alunos com necessidades educativas especiais, na incorporação na sociedade de cidadãos marginalizados, na eliminação do trabalho infantil, na abolição da prostituição, enfim, de todos os sinais marginalizantes ou excludentes. Poder-se-á concluir que fatores de exclusão existirão em qualquer parte da nossa sociedade, quanto mais não seja, pelo facto de não podermos intervir, ativamente, nos processos de decisão a todos os níveis. Deixamo-los, sempre, para os outros, para aqueles que detêm ou sempre dispuseram do poder de decidir. A sociedade está dividida, de facto, numa minoria de incluídos e numa maioria de excluídos. A prática coletiva de música constitui-se num referencial essencial, num quadro exemplar daquilo que pode revelar-se como um processo, que gostaríamos mais de chamar de compreensão, de tomar parte de algo, afastando-nos do sentido etimológico latino de inclusão que vem de includere, "fechar em, inserir, rodear, colocar alguém dentro de outro espaço/lugar”, realçando o facto de que esse verbo latino, por si só, é a síntese do prefixo in com o verbo cludo, cludere, que significa "fechar, encerrar", para nos transferirmos para um sentido mais abrangente e significativo de integrar, do latim integrare, significando "formar, coordenar ou combinar num todo". É nesse sentido de integração, de reunião, que a música levará a criança ou o jovem à capacitação do acesso ao conhecimento, preparando-o para o prazer de estar com o outro, porque a realidade social deve ser entendida como uma construção de significados, "[...] elaborada por cada uno de los participantes en una situación sociocultural y en relación com otros miembros activos de esta situación” (RAMIREZ, 1994, p. 11). 
Mas a sala de aula musical confronta-se com a existência de um único especialista, tentando dar resposta à diversidade de alunos, numa heterogeneidade cultural, portanto, também, social e com capacidades e necessidades variadas, ao que Breyer responde que "[...] uma sala inclusiva necessita de, no mínimo, dois educadores $(2005$, p. 31). As bases do nosso sistema conceptual educativo estão arreigadas às experiências pessoais que são, portanto, "[...] ideas parciales y particulares que alumbram determinados aspectos y oscurecen otros" (RAMIREZ, 1994, p. 12), a que acrescem os contextos físicos, condicionadores, "como una dimensión de la cultura integradora y/segregadora" (idem, p. 92), mas que deviam ser entendidos como recursos conceptual e ideologicamente poderosos para a integração plena. E Souza (2000) considera, ainda, que a aula de música deve ser transformada numa ação significativa, mantendo uma ligação e um confronto com a realidade, o que o ensino formal, frequentemente, escamoteia dos seus alunos, ou porque impera a formalidade curricular, ou porque, mais modernamente, transformou-se a educação musical num negócio fluorescente, a partir, por exemplo, das práticas de ensino articulado. Fortalece-se, mas erradamente, que somente quem possua habilidades específicas consegue ser musicalizado e treinado, por exemplo, para integrar uma ação coletiva de música a partir de uma orquestra sinfónica, porque esta tem o poder inabalável de um currículo integrador "[...] baseado em atividades que permitem o aluno aprender, fazendo" (PORTER, 1997, p. 44).

\section{$2^{\circ}$ Argumento}

\section{"O Lugar da Dança"}

É indispensável que o ambiente em que se pratica música constitua a essência agregadora, abrindo caminhos para a escuta e para a produção musical, afirmando Karagiannis que "[...] o 
ensino inclusivo é a prática da inclusão de todos - independentemente do seu talento, deficiência, origem socioeconómica ou origem cultural” (1999, p. 21). Não será uma missão fácil ou cómoda fazer música a partir das possibilidades de cada criança, mas, seguramente, será um ato enriquecedor e intencional.

Nessas condições, objetiva-se a Orquestra como dispositivo natural e uma das mais belas construções coletivas da nossa civilização. Etimologicamente, a palavra orquestra é de origem grega e significava "[...] o lugar para dançar”. Na tragédia grega, a orquestra fazia parte do palco, que fazia fronteira com o anfiteatro, onde se encontrava o público. Assim, a nossa civilização adotou o nome de Orquestra para o conjunto instrumental que se coloca próximo ao anfiteatro e que começou a ser usado na renascença, quando nascia a ópera, e esta necessitava de um conjunto instrumental, situado entre o palco e o anfiteatro, espaço para o público.

Na Antiga Grécia, entendia-se que o valor da música estava na possibilidade de formação e aperfeiçoamento do caráter e da cidadania, no sentido da ordem e da organização, na dignidade, no equilíbrio, na capacidade de tomar decisões e no profundo respeito pelas relaçôes com os outros. E, afinal, nada melhor do que expor a prática orquestral a uma política de integração, pela partilha de experiências culturais e de dinâmicas de aprendizagem. Se a escola deveria ser um canal em direção à mobilidade ascendente, superando contradições socioeconómicas, o que ainda, dificilmente, consegue fazer, então, a Orquestra educando e ensinando todos por igual, nas suas diferentes competências, pois todos aqui têm um papel significante a desempenhar, conduz, simultaneamente, ao tempo individual e coletivo, estimulando uma participação democrática em que cada um sabe ouvir, tem de cooperar, deve intervir e está obrigado a respeitar.

A Orquestra representa-se por um espaço de microssociedade, onde o compromisso, o desenvolvimento da vontade, a partilha e a cooperação fundem-se numa plataforma de interesses comuns. De notar que, na prática orquestral, os participantes, 
dois a dois, leem pela mesma partitura, partilham da mesma estante e integram a mesma comunidade. Há um ultrapassar de fronteiras, um exercício de pensar em singularidades, um contimuum de dentro e fora, num exercício entre o passado e o futuro, único espaço/tempo onde se pode permutar ou recriar, já que o presente é uma construção individual. Há uma fina camada que separa o palco do anfiteatro, que medeia entre a orquestra e o público e, nesta circunstância, os músicos empreendem um valor poderoso de ir até o fora, através da sua amabilidade, da sua influência sonora, da sua resiliência ao imediato, sendo aquilo a que Maurice Blanchot chama de "a paixão do fora", uma força que só tende para o fora, porque o próprio fora se tornou a "intimidade”, a “intrusão" (1969, p. 64-66). É nesse complexo que a Orquestra funciona, é por tal que ela é importante, porque aquele fora informal, câmara central da ação, "[...] é uma batalha, é como uma zona de turbulência e de tempestade onde se agitam pontos singulares e relações de forças entre esses pontos” (DELEUZE, 2012, p. 163). É o tempo do renascimento, de voltar às origens da Orquestra e fazer dela, mais do que um espaço de conveniência, um lugar de confluência.

Curiosamente, sendo a Orquestra um instrumento dos mais antigos e mais usados na comunicação, aperfeiçoado pelas épocas que tem atravessado, construído sobre obras de inesquecível perfil musical, julgamos que não tem merecido a devida análise em termos da sua construtura interior e exterior e não tem sido construído um centro de semiótica que permita entendê-la nas suas relações, com o público, como signo e como realidade. Ela se situa entre uma essência de objeto, o representamen, embora não se confunda com ele, mas que se materializa através dele, e um resultado que parte do interpretador (o público), $o$ interpretante, que se emociona, que se reconstrói a cada movimento sonoro. Esse pensamento leva-nos a concluir que estamos perante um poderoso meio, simultaneamente, de comunicação e de participação, como unidade celular única, espessa e complexa, que se apronta por uma tensão entre os seus dois elementos 
principais, um de ordem externa, o público que a acolhe (a orquestra) e outro de ordem interna (os músicos/participantes) que são responsáveis por uma dinâmica interativa, por uma relação discursiva-dialógica. Será que existirá uma conformidade de parceria, entre orquestra e público? Será que cooperação e concorrência orientam o percurso dos dois, orquestra e público? E, se sim, que lugar para os músicos? Simples veículos? Também serão uma espécie de interpretante, não como reprodutores (interprete), mas sim, como atores que intervêm no processo de reconstrução do diálogo? Parece-nos que a tensão fractal é, afinal, o elo que liga os dois elementos, num caráter espiralado e infinito. Só assim, a Orquestra será valor, muito mais do que reprodutor, ou formador, que Peirce não hesitaria em questionar, se objeto imediato, ou objeto dinámico.

A Orquestra, como espaço de conexões, parte de uma acção organizada - músicos, naipes orquestrais, maestro - por uma rede intrincada de objetivos e relações, obrigando à mudança, por vezes, das redes de sociabilidade. Traçam-se, então, novos ideais e formam-se novos modelos, de forma dialética, vinculando decisões individuais a um contexto reticular, tentando cada participante subir acima dos estratos, para chegar a um fora, procurando explicar como duas formas de saber - individual e coletiva - podem-se entrecruzar e originar novos enunciados. Para Velho (1994, p.103), “[...] o projecto orquestral pressupõe a existência do Outro. Mas, sobretudo, o projecto é o instrumento de negociação da realidade com outros atores, individuais ou coletivos" (1994, p. 103).

Dois projectos individualizam-se no panorama das orquestras, ditas, de inclusão: O Sistema Nacional de Orquestras e Coros Juvenis e Infantis da Venezuela ${ }^{1}$ e a Orquestra Geração ${ }^{2}$. Os dois projectos encontram-se ancorados numa dependência estatal, recebendo apoios oficiais e colhendo, ainda, contribuições de outros organismos para a aquisição de instrumental, como é o

\footnotetext{
É uma obra social do Estado Venezuelano.

2 Projecto orquestral inspirado no Sistema venezuelano de orquestras juvenis.
} 
caso da Fundação EDP, no que respeita à Orquestra Geração. Não deixam, ambas, de se terem transformado, sob o ponto de vista funcional, educativo, artístico e administrativo, num conjunto alargado de núcleos e orquestras, abrangendo, nos dois países, Venezuela e Portugal, grande parte do território, envolvendo um assinalável número de crianças e jovens. No que toca à Orquestra Geração, esta encontra-se associada, por um ensino formal, a conservatórios e outras escolas de música.

O sistema venezuelano encontra-se disseminado em distintas partes do mundo como modelo de educação musical e orquestral e, pese embora todo o reconhecimento que tem por parte de muitas das entidades internacionais, corre o risco de ser portador de uma bandeira nacionalista e a serviço dos estados. Para além do mais, a massificação que produziu, por uma quantidade assinalável de participantes, e imitada em outros lugares, pode, de algum modo, condicionar ou mesmo anular outros projectos de natureza semelhante que, agora, não vão caber nas prioridades dos estados, seja ao nível nacional, seja ao nível das municipalidades. Se atentarmos bem, a grande bandeira da política venezuelana, no campo cultural, é, precisamente, o Sistema de Orquestras, sendo o cabeça de cartaz internacional, o maestro Gustavo Dudamel, produto do sistema e ídolo de massas, o que, curiosamente, é a primeira vez que acontece, no campo da música clássica ${ }^{3}$, quando esse tributo é entregue, normalmente, a músicos ligados ao rock.

A Orquestra Geração, numa iniciativa conjunta da Escola de Música do Conservatório Nacional, Câmara Municipal da Amadora e Fundação Calouste Gulbenkian, já estendeu a sua ação a outras zonas do país, criando uma teia de grupos e pequenas orquestras e de relações com agrupamentos de escolas do ensino regular, êxito que se pode compreender pelo alcance e natureza do projeto, mas também, porque, através das autarquias e mecenas, os instrumentos são oferecidos aos participantes.

3 De notar que o Sistema venezuelano foi criado antes de Hugo Chavez chegar ao poder. 
Pode existir, nesta ação global, um somatório de relações que, nomeadamente, o Estado não desejando explicar do poder exercido, vai conduzindo e condicionando aquela intervenção. Regressando a Foucault, a força de poder "[...] nunca existe no singular, pertence à sua essência estar em relação com outras forças" (DELEUZE, 2012, p. 97). E, por tal, parece-nos existir uma segmentaridade na ação desses projetos, pois conciliam massificação, com dependência estatal e ensino formalizado. Se o saber diz respeito a substâncias, “[...] o poder não passa por formas, mas apenas por forças” (idem, p. 101).

Mas o que aproxima aqueles dois projetos orquestrais é a tendência para a massificação, o aumento, quase que se diria em exponencial, do número de envolvidos e do número de orquestras, num quadro de comparação, aliás, o que se verifica nas inúmeras afirmações dos seus responsáveis. Não é que proporcionar espaços de participação para miúdos sem acesso à prática coletiva de música não constitua, em si mesmo, uma ação importante para o crescimento daqueles, mas o lastro que se tece com aquele tipo de resultados é o confinar-se à ideia de ídolo ou de referência particular, o que diminui o espaço de liberdade e de opção. Fazendo uso da teoria das necessidades culturais, os sistemas tradicionais de comportamento organizado vivem na base de como "[...] os estímulos, as atividades e as satisfações se processam de facto, no âmbito do cenário cultural” (MALLINOWSKY, 2009, p. 95). Quando oferecem-se, por exemplo, instrumentos musicais, na contrapartida da participação na orquestra, está-se a diminuir o grau de comprometimento e a aumentar a natureza da responsabilidade e tal, só poderá ser concretizado debaixo de determinadas condiçôes, muito particulares.

Em termos de análise funcional, qualquer resolução ou revolução ocorre quando criadas novas necessidades e, assim, " [...] quer surja como invento, quer seja difundido, um novo engenho técnico infiltra-se no sistema de comportamento organizado pré-existente e, aos poucos, transforma por completo essa instituição” (MALLINOWSKY, 2009, p. 51). Não se deseja, então, 
que a vida na orquestra e as conexões estabelecidas derivem para uma certa entrega a um ato comercial ou industrial. $\mathrm{O}$ que se passa no contexto orquestral é um conjunto de sequências rituais", que fazem da música "uma máquina de aniquilação do tempo", numa observação de Lévi-Strauss, porque o resultado orquestral estará mais na combinação das diferentes linhas melódicas da obra, "[...] o público de uma orquestra interessa-se pelo trabalho conjunto de todos os instrumentistas e do maestro. Não é nas linhas melódicas dos instrumentos isolados que reside o sentido da música” (LEACH, 2009, p. 66). Essas novas orquestras, a que nós chamamos de "integração", devem, então, colocar o foco da sua ação no todo do coletivo, dispensar os elogios e as eleições de especiais, embora os possa/deva produzir, mas sem que isso concorra para o estabelecimento de qualquer altar de predestinados. Podemos, pois, deduzir que só "[...] os signos e os símbolos transmitem sentido em combinação e não apenas enquanto conjuntos de signos binários, dispostos em sequência linear, ou como conjunto de símbolos metafóricos associados de forma paradigmática” (LEACH, 2009, p. 132).

Por fim, a Orquestra não se trata de um qualquer umbral fisiológico, existe, de facto, uma comunicação de substâncias, "uma conexão da alma e do corpo", porque "[...] os sons não só se ouvem, senão que se sentem com certas qualificações afetivas" (PARDO, 2008, p. 58). E aqui, antevê-se a corrente sanguínea, o espetro de turbulências que chocam com fluxos que nos chegam do exterior, do fora. A Orquestra é feita de um repertório de diferentes espacialidades e temporalidades, como a temporalidade das flores, cujo ritmo desdobra-se no crescimento e nos ciclos reprodutores. Tal e qual como na Orquestra, em que integração significará combinação de espaços e de tempos e na qual participação se apresenta como uma unidade composta por numerosas partes iguais. E como volta Prado a especular sobre o sentido do comum, na sua profundidade poética, descrevendo que "[...] a nossa morada está feita de músicas, refrãos, a nossa casa é uma

LEACH, E. “Cultura e Comunicação”. Lisboa: Edições 70, 2009, p. 63-66. 
deformação do nada, uma prega do caos, uma turbulência do tempo ou um remoinho do espaço, um repertório de formas e figuras, de ritmos e posturas" (PRADO, 2008, p. 63-64). E porque, só na prática coletiva de música, através da Orquestra, poder-se-á alcançar o verdadeiro sentido da participação: receber algo de outrem!

\section{$3^{\circ}$ Argumento}

\section{Um caso para estudo}

A Orquestra Juvenil de Gaia é, certamente, um projecto singular que se tem desenvolvido nos últimos quatro anos, criado no dia 1 de outubro de 2008, numa parceria de escolas do concelho de Vila Nova de Gaia, mas numa iniciativa da sociedade civil, com acolhimento da Escola Básica de Santa Marinha.

Reconhece-se que essa iniciativa constitui um projecto-piloto em nível nacional, marcadamente eclética e não se envolvendo com quaisquer critérios estéticos especiais ou preconceitos musicais. Trata-se de um projecto de integração a partir da prática coletiva de música, em que os meninos e as meninas que não têm possibilidade de acesso à fruição musical adquirem, aqui, oportunidades de partilha dos seus sentimentos, da sua vontade e caminham para o exercício da responsabilidade individual e coletiva. Esta Orquestra funciona como uma espécie de laboratório musical, no caminho de um grande Estúdio de Orquestra - iniciativa pioneira, à volta do que se envolvem projetos especiais, a criação futura de um museu do som, um estúdio de gravação adstrito a uma hemeroteca, fundamentalmente, sobre práticas orquestrais e um novo sistema de codificação musical (A Numerofonia) - atenta às características dos seus participantes diretos - alunos do ensino regular - mas que não deixará, por isso mesmo, de atender às exigências de promoção dos alunos, como executantes e futuro público. A entrada de crianças e jovens não obedece a qualquer critério técnico-musical e muito menos à 
consideração da sua situação socioeconómica, na base de meninos ou meninas desfavorecidos ou portadores de deficiência, eliminando, assim, princípios normativos de acesso inclusivo, sendo a esmagadora maioria dos participantes crianças sem qualquer conhecimento mínimo de prática instrumental e, em muitos casos, competências musicais.

A natureza do projecto obrigou ao desdobramento em três partes, a Orquestra Sinfónica Juvenil de Gaia, a Orquestra de Cámara de Gaia e a Pequena Orquestra de Câmara, três braços que se complementam, podendo o primeiro ser observado por um ângulo da participação e da promoção pelo gosto e prazer musicais, o segundo, envolto num perfil mais artístico, dando possibilidade a que os jovens mais vocacionados para a prática musical vejam na Orquestra de Câmara uma oportunidade de valorização dos seus conhecimentos e de suas práticas, assumindo uma participação simultânea com grande parte dos professores e o terceiro, um compromisso mais atento a pequenas aptidões e interesses particulares na prática instrumental, sem que isso indique uma perseguição sem critério ao talento musical insignificante. A partir desta valência, o projeto deu oportunidades a que alguns pudessem continuar os seus estudos musicais em escolas especializadas, permitindo crescimento das suas expectativas individuais.

A formação nunca deixou de constituir um dos pilares essenciais no desenvolvimento do projeto, em que a Escola de Orquestra tem um papel fundamental, porque permite, por um lado, o aperfeiçoamento técnico dos alunos, mas, por outro, possibilita que eles compreendam e se deixem seduzir pela importância que uma orquestra anuncia, em termos de aprendizagem, responsabilidade partilhada e respeito pelo esforço e trabalho. Por isso, a equipa de professores de naipe declara-se como instrumento decisivo no desenvolvimento de todo o plano orquestral, sendo, cada um deles, par de cada menino ou menina, na Orquestra Juvenil. 
De referir que a matriz do projeto assenta na participação aberta de meninos e meninas, com ou sem conhecimentos e experiências musicais e fora de qualquer compromisso com modelos de ensino, nomeadamente, do ensino articulado de música, não se configurando, o projeto da Orquestra Juvenil, como angariador de clientes, como seu sustentáculo, económico ou artístico. Por outro lado, e isto assume-se como a maior riqueza do projeto, não o condicionando na sua matriz essencial de liberdade, porque os compromissos parecem assumir-se de fora para dentro, nunca existiu a intenção ou o hábito de concessão livre e universal de qualquer tipo de instrumentos, salvo a circunstância particular de alguma criança não possuir, mesmo, condições de aquisição. Por tal, verificou-se que todos os participantes adquiriram, individualmente, o seu instrumento e isso nunca foi problema elevado para a impossibilidade de participação na Orquestra Juvenil de Gaia, o que contraria a prática habitual de outros projetos, que encontram na entrega de instrumental, uma forma de compromisso. Por esta forma, também, os encarregados de educação foram parceiros ativos no desenvolvimento do projeto, facto de assinalar, o que, habitualmente, não se revela de inovador esta cooperação, a avaliar pela ausência de relevo nas propostas, atrás, referidas.

$\mathrm{O}$ ensino articulado tem nas suas finalidades primeiras a divulgação do ensino artístico e a facilitação do seu acesso a um maior número de crianças e jovens, que o podem frequentar na sua escola de ensino regular e numa outra de ensino especializado. Não tem sido pacífico este entendimento, não pelos seus pressupostos teóricos, mas sim pelas práticas seguidas, fazendo dele um negócio fluorescente para muitas escolas especializadas. Há que se procurar entender qual tem sido o impacto deste tipo de ensino, não sendo, no entanto, este espaço o local para o aprofundamento desta matéria, quais os problemas que ele tem manifestado, se existem pressão pelos condicionantes de frequência, tanto ao nível dos alunos como dos professores, obrigando o aluno a passar, independentemente da aquisição das competências mínimas. Assim, muitas das escolas e dos projetos que desenvolvem são 
localizados, restritos e suportados, então, nos alunos do ensino articulado, levando a banalizar as suas especificidades. Por vezes, não é fácil a distinção entre o facto de percebermos se é o ensino articulado que suporta a viabilidade técnica e social de alguns projetos, como são as orquestras de integração, se são estas que existem para justificar o funcionamento do ensino articulado. Mas, também aqui, a Orquestra Juvenil de Gaia distingue-se dos outros dois projetos, pois não depende de qualquer programa de ensino especializado, acolhendo, fundamentalmente, meninos e meninas que desejam participar numa ação coletiva de música, através de uma Orquestra Sinfónica, não enjeitando, claro está, qualquer aluno do ensino articulado.

Este projeto de integração parece ter-se pensado e estruturado à volta de uma ideia essencial, que é o voluntariado, pois toda a equipa de professores e colaboradores, que ascende a, quase, vinte pessoas, é, praticamente, recompensada a custo zero, mas mantendo uma regularidade na sua presença de acompanhamento e apoio técnico a noventa meninos e meninas, participantes do projeto e divididos pelos mais variados naipes orquestrais. Não é que se entenda que a participação voluntária não deva ser reconhecida ou, mesmo, considerada em alguns dos custos de participação cívica, mas exige-se que ela não se transforme num negócio ou oportunismo, que proliferem sob a capa de tributo cívico, devendo, por isso, ser encarado algum ressarcimento de despesas do voluntário, o que assegurará a minimização de custos, eventualmente, dispendidos. Projetos desta natureza só poderão conhecer a sua eficácia e a responsabilidade social se o voluntariado for o porto de partida para as açôes de consciencialização e comprometimento social. A Orquestra Juvenil de Gaia parece ter entendido o problema e suportou a sua ação naquela evidência, o que a distingue dos dois outros projetos anteriormente descritos que vivem suportados numa equipa profissional de professores e outros técnicos. Estamos perante, seguramente, uma feliz inciativa da sociedade civil. 


\section{$4^{\circ}$ Argumento}

\section{Um encerro possível}

Conclui-se que será um enorme erro fazer depender este tipo de orquestras do poder instituído, seja ele nacional ou local. Contudo, não se deseja, também, que as instituições oficiais se afastem das preocupaçôes dos promotores daqueles projetos, pela responsabilidade que lhes cabem, pelo menos, no reconhecimento da sua importância social. A relação pedagógica só alcança o seu verdadeiro valor se construída em ambientes culturais heterogéneos, na miscigenação de múltiplas etnias, representações, pronúncias, valores diferentes. Porém, aquela deve ser de movimento binário e deverá de ser examinada a partir de bases pós-modernistas.

A escola deveria olhar mais e melhor para essas Orquestras Juvenis, acolhê-las no seu seio, como um dos modos de enfrentar e operacionalizar alternativas de participação, mas como matérias de consideração pedagógica e curricular. Se a identidade se estabelece por uma construção relacional, então a Orquestra é um sistema de representação que abre espaço, onde os indivíduos podem-se posicionar face ao valor híbrido da participação. Através dela, serão dados subsídios e orientações, de modo, os pequenos participantes confrontem-se com as suas potencialidades, mas isso não significa uma mera relação técnica com a música. Uma educação musical formadora, excessivamente controlada, conduz a um processo educativo desmobilizante, cujos projetos examinados - o Sistema venezuelano, a Orquestra Geração e a Orquestra Juvenil de Gaia - poderão constituir base de análise e de investigação mais aprofundada, no seu valor, tanto aparente quanto potencial.

Também, dever-se-á chamar a atenção para o facto de se correrem riscos desnecessários, se se permitir que o desenvolvimento desses projectos de prática coletiva de música, deixem-se conduzir para a produção de um resultado final, com preocupações de 
visibilidade e autoatribuição de glória, efémera. $\mathrm{O}$ fio condutor desta realidade, que começa a pulverizar o país, deve ser assumido na reconstrução da realidade emergente de todos.

Neste tipo de projeto, é determinante a criação de redes sociais, nomeadamente, aquelas que provêm dos núcleos familiares, porque, próximos dos músicos e da Orquestra, podem comprovar dos benefícios que ela arrasta para os seus educandos, contrariando estereótipos e preconceitos sobre o valor ou não das atividades orquestrais. Sendo, neste contexto, a educação musical uma unidade menor, a Orquestra, como projeto social e as políticas públicas, devem saber realizar a transformação social, cultural e económica de uma comunidade de meninos e meninas. Seremos, sempre, adeptos de uma independência de qualquer poder público e político, porque não poderemos deixar de perceber os projetos orquestrais, como

[...] um conjunto de iniciativas privadas com fins públicos e sociais, não lucrativos, que buscam formas de enfrentamento das questóes sociais vividas por uma grande parcela da sociedade privada, tanto de bens materiais, como simbólicos (KLEBER, 2006, p. 2)

Carlos Kater (2004) considera, em forma de advertência, que, em muitos dos casos, a música converte-se em mera panaceia de integração social e vira em simples ocupação, transformando-se num lugar vazio. Vazio de potencial educativo, vazio de valor cooperativo, vazio de nada!

\section{Referências}

BEYER, Hugo Otto. Inclusão e avaliação na escola: de alunos com necessidades educacionais especiais. Porto Alegre: Mediação, 2005.

BLANCHOT, Maurice. L'entretien infini. Paris: Gallimard, 1969.

BOURDIEU, Pierre. La Misère du monde. Paris: Minuit, 1993.

DELEUZE, Gilles. Foucault. Lisboa: Edições 70, 2012 
GAINZÀ, Violeta Hemsy. Estudos de psicopedagogia musical. São Paulo: Summus, 1988.

KARAGIANNIS, Anastasios; STAINBACK, Wiliam; STAINBACK, Susan. Fundamentos do Ensino Inclusivo. In: STAINBACK, W; STAINBACK, S (Org). Inclusão, um guia para educadores. Porto Alegre: Artmed, 1999. p. 21-31

KATER, Carlos. O que podemos esperar da educação musical em projetos de ação social. Disponível em: <www.abemeducacaomusical.org.br/ Masters/revista10/revista10_artigo6.pdf.>. Acesso em 11 nov. 2012.

KLEBER, Magali Oliveira. Educação musical e ONGS: dois estudos de caso no contexto urbano brasileiro. In: Pauta, v.17; n. 29, jul./dez. 2006. Porto Alegre: Curso de pós-graduação em Música/UFRGS.

LEACH, Edmund. Cultura e comunicação. Lisboa: Edições 70, 2009.

LEVINAS, Emannuel. Ethique et infini. Paris: Fayard, Radio France, 1982.

MALLINOWSKY, Bronislaw. Uma teoria científica de cultura. Lisboa: Edições 70, 2009.

PARDO, José Luís. Fora da filosofia. Lisboa: CFCUL, 2008

PORTER, Gordon. Organização das escolas: conseguir o acesso e a qualidade através da inclusão. In: Caminhos para as escolas inclusivas, IE, 1997.

RODRIGUES, David. (Ed.). Perspectivas sobre a inclusão: da educação à sociedade. Porto: Porto, 2003.

VELHO, Gilberto. Projeto e metamorfose: antropologia das sociedades complexas. Rio de Janeiro: Jorge Zahar, 1994 